\title{
The Egg and the Nucleus: A Battle for Supremacy
}

\author{
J. B. Gurdon, F.R.S., F.Med.Sci.* \\ The Gurdon Institute, University of Cambridge, UK
}

\section{POST-NOBEL PERSPECTIVE}

This brief introduction is followed by a published version of my Nobel Laureate lecture, re-published herein with the kind permission of the Nobel Foundation. Much has happened since my original research, for which that prize was awarded. Hence, I am pleased to offer a few thoughts about the future of my research and its possible impact on humankind.

Although the original work on nuclear transfer and reprogramming was done over half a century ago, advances continue to be made. In particular the Takahashi and Yamanaka induced pluripotent stem cells (iPS) procedure has opened up the field of cell replacement to a great extent. Now, more recently, further advances make this whole field come closer to actual usefulness for humans. Recently, in the UK, the government approved the use of mitochondrial replacement therapy to avoid the problems associated with genetically defective mitochondria in certain women. Although the House of Commons (members of Parliament) and the House of Lords had to debate and discuss whether to allow this kind of human therapy, I was very pleased to find that both bodies approved this procedure. This means that a patient can choose to make use of the procedure; it does not in any way force an individual to have a procedure that they are not comfortable with. In my view, this is a great advance in respect to giving patients a choice about the treatment they receive. I am told that the UK is the first country in the world to approve mitochondrial replacement therapy.

\footnotetext{
Abbreviations: CRISPr, clustered regularly interspaced short palindromic repeat; FRAP, ferric reducing ability of plasma; iPS, induced pluripotent stem cell.
}

Citation: Gurdon JB. The Egg and the Nucleus: A Battle for Supremacy. Rambam Maimonides Med J 2015;6 (3):eoo23. doi:10.5041/RMMJ.10208

Copyright: (C) 2012 Nobel Foundation and (C) 2015 Gurdon for the section entitled "Post-Nobel Perspective." Source: Nobelprize.org.

Acknowledgement: Rambam Maimonides Medical Journal wishes to thank the Nobel Foundation for their permission to reprint Sir John Gurdon's Nobel Laureate lecture. The content of this paper, with the exception of the opening section "Post-Nobel Perspective" is a faithful reproduction of that lecture given on December 7, 2013, and reformatted according to the journal standards.

Conflict of interest: No potential conflict of interest relevant to this article was reported.

* E-mail: jbg10oo@hermes.cam.ac.uk 
Now that the Clustered Regularly Interspaced Short Palindromic Repeat (CRISPr) technology is being widely used and works well, one can foresee that there will be those who wish to use this technology to make genetic changes to humans. For example, if a human has a gene that makes it susceptible to infection or any other disorder, the removal of that gene might give such a person immunity from that disease. If this gene deletion is done within the germ line, the genetic change will be inherited. However, one can imagine that various people will strongly object and say that this technology should not be allowed. I would very much hope that various regulatory bodies, governments, etc. will allow the choice to remain with the individual. I can see no argument for such bodies to make a law that removes any choice whatsoever by an individual.

KEY WORDS: Nuclear transfer, pluripotent stem cells, Xenopus laevis

\section{BACKGROUND}

When I was a brand new graduate student starting in October 1956, my supervisor Michail Fischberg, a lecturer in the Department of Zoology at Oxford, suggested that I should try to make somatic cell nuclear transplantation work in the South African frog Xenopus laevis. There were good reasons for wanting to do this (see below). The very important question to be addressed at that time was whether all cell types in the body have the same set of genes. This question had been asked by embryologists since 1886, ${ }^{1}$ and Spemann ${ }^{2}$ had demonstrated by an egg ligation experiment that the nuclei of an eight-cell frog embryo are developmentally totipotent. It was clear that a definitive experiment required the replacement of a zygote nucleus by a somatic cell nucleus, asking whether the somatic nucleus could functionally replace the zygote nucleus by eliciting normal development of the enucleated recipient egg (Figure 1). Briggs and King3 had already succeeded in transplanting a blastula cell nucleus into an enucleated egg and obtaining normal tadpoles in the frog Rana pipiens. However, Briggs and King 5 had also found that the nucleus of an endoderm cell from a neurula embryo could no longer support normal development (Figure 2). They drew the reasonable conclusion that, as development proceeds from a blastula to a neurula stage (about 24 hours), some genes needed for normal development had either been lost or irreversibly repressed.

To this extent, the aim of my proposed PhD work had already been done and the answer to the primary question already obtained. Why then did it make sense for me to try to repeat this work on a related species? There appeared to be two possible outcomes. One was that I might obtain a different result from Briggs and King and so the primary question would be re-opened and subject to fruitful investigation. The other was that I might obtain the same result as Briggs and King and this would then open the important question of what the mechanism could be by which a somatic cell nucleus already committed to a specific (in this case endoderm) fate could not be reprogrammed by exposure to egg cytoplasm.

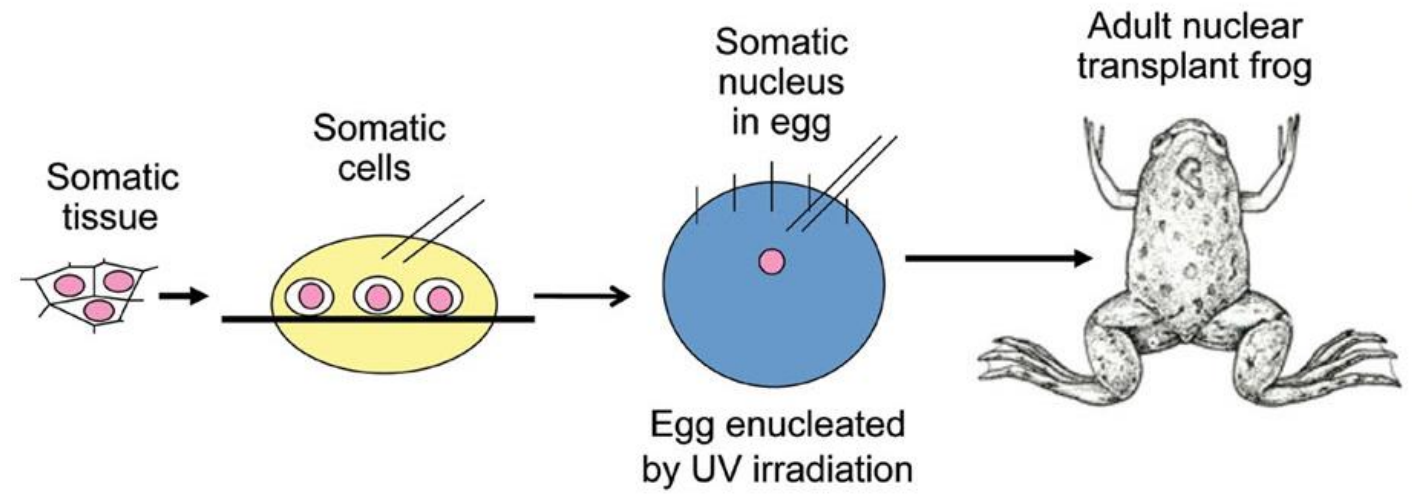

Figure 1. Design of a Somatic Cell Nuclear Transfer Experiment using Unfertilized Eggs as First Designed by Briggs and King $^{3}$ for Rana pipiens and as used Subsequently in Xenopus.

In Rana, enucleation is by hand with a needle, and in Xenopus by ultraviolet light irradiation. ${ }^{4}$ 


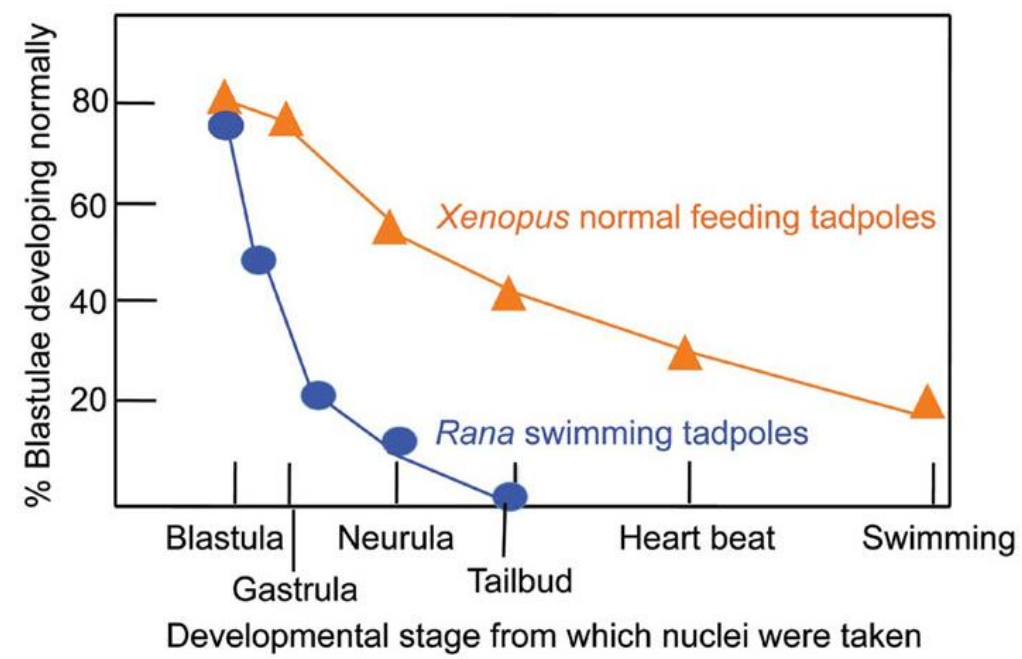

Figure 2. Survival of Nuclear Transplant Embryos in Rana pipiens and Xenopus laevis.

Even advanced donor cells from the endoderm have nuclei which can sometimes yield normal individuals after nuclear transfer (from Briggs and King $[\text { Rana }]^{5}$ and Gurdon $[\text { Xenopus }]^{6}$ ).

Preliminary investigation showed that there would be substantial technical difficulties in achieving somatic cell nuclear transfer with Xenopus, in the way that Briggs and King succeeded for Rana pipiens. The first of these was that, unlike Rana, the Xenopus egg is covered with a dense and extremely elastic jelly, which is completely impenetrable by even the finest of micropipettes (Figure 3). The second was that this jelly covering made it very hard, even if possible, to remove metaphase egg chromosomes by causing extrusion of them with a needle, the method used in Rana pipiens. There were, on the other hand, very good reasons to wish to make this technique succeed in Xenopus. How Xenopus laevis, a native of South Africa, came into use for developmental biology has an amusing and serendipitous history.7 First, Xenopus would respond to the injection of commercially available mammalian hormone (follicle-stimulating hormone and luteinizing hormone) by laying eggs the next day, and this procedure is effective throughout the year. In contrast, frogs of the European and North American Rana species will lay eggs only in the spring of each year unless they are injected with frog pituitary gland extract, and this requires about five pituitary glands from killed frogs to obtain one egg ovulation. In the past, European embryologists had the use of living frog eggs for only a month or two in the year and had to do other things, such as histology etc., for the rest of the year.Xenopus, in principle, permitted experiments on living embryos to be done throughout the year. Second, Xenopus is an aquatic frog and therefore easy to maintain in the laboratory in water tanks rather than having to clean a terrarium as was necessary with Rana. Furthermore, Xenopus species can be reared from the fertilized egg to sexual maturity in less than one year (compared to three to four years for Rana), thereby making it realistic to propagate genetic mutants and make use of them. A further advantage of Xenopus laevis is that this species lives in highly infected cattle sewage ponds and has built up an extraordinary resistance to infection and diseases. Michail Fischberg therefore concluded that it was sensible to have me try, at least for a while, to achieve successful somatic cell nuclear transfer in Xenopus.

The aim of this article is to recount the early history of nuclear transfer in Xenopus as a result of which the recent Nobel award was made. ${ }^{8}$ Further work in Xenopus that has led on from this up to the present time is covered only briefly, and has been reviewed elsewhere.9,10

\section{THE TECHNIQUE OF NUCLEAR TRANSFER IN XENOPUS}

There is no doubt that I was blessed with a considerable amount of luck. But the phrase that "luck favors the prepared mind" may well have been true. My supervisor had just acquired a microscope equipped 

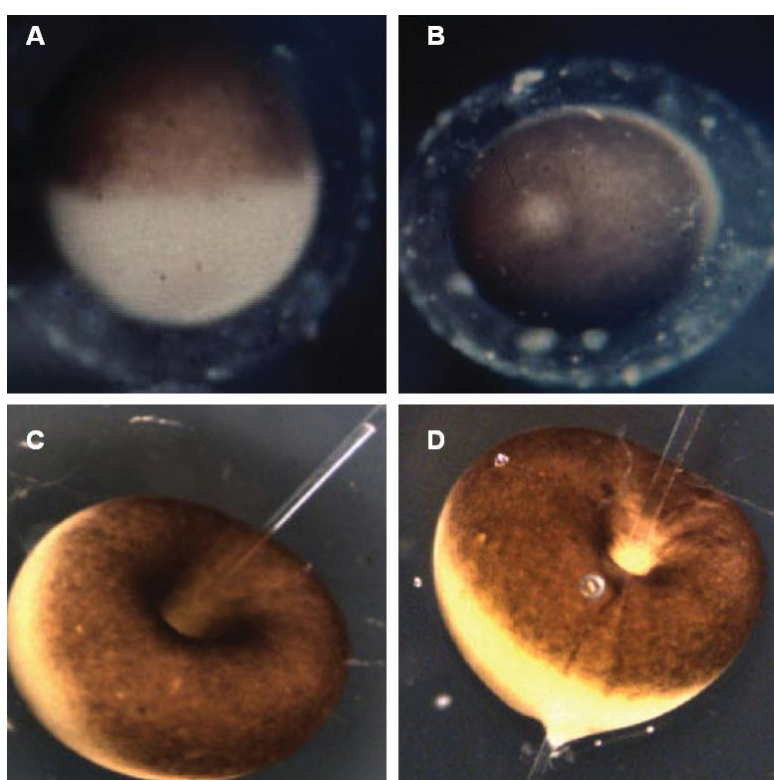

Figure 3. Xenopus Egg Images.

The Xenopus egg is surrounded by a dense elastic jelly so that it is not possible to penetrate into the egg cytoplasm with a micropipette, unless the jelly is removed or denatured by ultraviolet light. (A) Side view. (B) "Animal" pole; the white area in the middle of the black area is where the egg chromosomes are located. (C) If the egg is not de-jellied, a micropipette depresses the jelly coat, eventually dragging the pipette, still surrounded by jelly, through the egg without entering the cytoplasm (D).

with ultraviolet light illumination. There was reason to believe that ultraviolet light would destroy DNA in the egg chromosomes which, very fortunately, are located right on the surface of the animal pole of amphibian eggs. Aiming the ultraviolet light source onto the animal pole of unfertilized eggs was successful in destroying the egg chromosomes, as shown by fertilizing such irradiated eggs with sperm and obtaining haploid embryos. If the egg chromosomes had not been located on the surface of a large amphibian egg, ultraviolet light (having very low penetration) would not have reached them. 4 Perhaps even more fortunate was our finding that the particular ultraviolet lamp just bought for microscopy progressively denatured (dissolved) the elastic jelly around the egg. After ultraviolet light exposure, unfertilized eggs became easily penetrable by a micropipette, and this happened in a dosedependent way, making it possible to enucleate the egg, leaving just enough jelly to help seal the penetration wound made by a micropipette. It was not known at that time that this egg jelly could be removed by an alkaline solution of cysteine hydrochloride, but good luck, or my supervisor's wisdom, or both, did not stop at this point. Crucial to the validity of these early experiments was proof that the egg chromosomes had in fact been destroyed and did not contribute to the development of the nuclear transplant embryos. Another PhD student of my supervisor, namely Sheila Smith, was studying the morphology of haploid development in Xenopus. She was advised to use a single nucleolus per nucleus as a measure of haploidy. She encountered a seemingly inexplicable result, namely that embryos carrying only one nucleolus per nucleus were diploid and developed entirely normally, whereas haploids (which have only one nucleolus per nucleus or chromosome set) always die as stunted early tadpoles. Most supervisors would have told the student to repeat the experiment the next week, starting with completely different material, to see if the result was reproducible. Michail Fischberg (Figure 4), however, had the wisdom or intuition to tell the student to find out which frog had been used to give the eggs that yielded normal diploid onenucleolated embryos. Amazingly, the student's result was reproducible. Michail Fischberg concluded that there must have been a mutation in one chromosome set so that it was unable to make a nucleolus. ${ }^{11}$ Later work showed that this strain of Xenopus had indeed lost all the ribosomal genes located in one nucleolus organizer and therefore that heterozygotes for this deletion would never

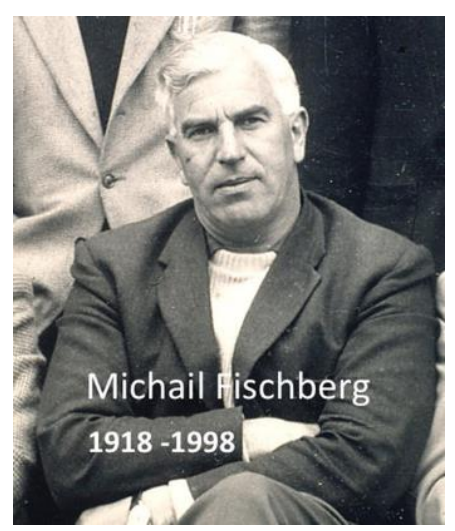

Figure 4. Michail Fishberg.

Born in St Petersburg, educated in Switzerland and PhD under $\mathrm{E}$. Hadorn. The education lineage traces back from Hadorn to Baltzer to Boveri. MF was my graduate supervisor in Oxford, England, from where he moved to Geneva. 
carry more than one nucleolus per diploid chromosome set. ${ }^{12}$ This mutation gave us an extraordinarily valuable nuclear marker for nuclear transfer experiments (Figure 5). Some years later, an albino strain of Xenopus laevis provided a more visually striking marker (Figure 6).

Using the benefits of ultraviolet radiation, combined with a genetic marker, it was possible, rather rapidly, to show that somatic cell nuclear transfer in Xenopus worked well. Within one year of starting work, I had found that the nucleus of an endoderm cell from an advanced tadpole was able to yield some normal development up to the nuclear transplant tadpole stage. This was not in agreement with the results of Briggs and King (Figure 2).

\section{NORMAL DEVELOPMENT FROM THE NUCLEI OF DIFFERENTIATED INTESTINAL EPITHELIUM CELLS}

Within another year, now 1958, I found that it was technically possible to transplant single nuclei from the intestinal epithelium of feeding tadpoles. I found it best to distort the donor cells to the least amount possible, ${ }^{13}$ so that at least some of them had the nucleus in a ruptured cell wall, even though other such donor nuclei may have been transplanted in whole non-permeabilized cells, which, however, would not be able to respond to the egg cytoplasm or

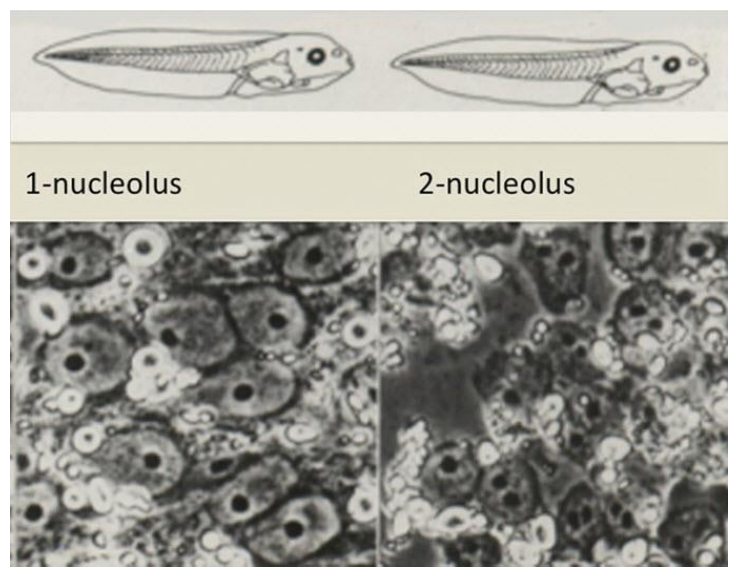

Figure 5. A Nucleolar Genetic Marker for Xenopus laevis (Elsdale et al. ${ }^{11}$ ).

Heterozygotes of the one-nucleolated strain have only one nucleolus per diploid nucleus (left), compared to the wild-type 2-nucleolated form most of whose nuclei have two nucleoli (right). The one-nucleolated strain has a deletion of ribosomal genes on one chromosome. ${ }^{12}$

begin to cleave. It seemed important not to expose the nucleus of a ruptured cell to the simple saline medium used for nuclear transfer. It was later found that treating small donor cells with streptolysin $\mathrm{O}$ was a great deal easier than cell rupture in a narrow pipette. ${ }^{14}$

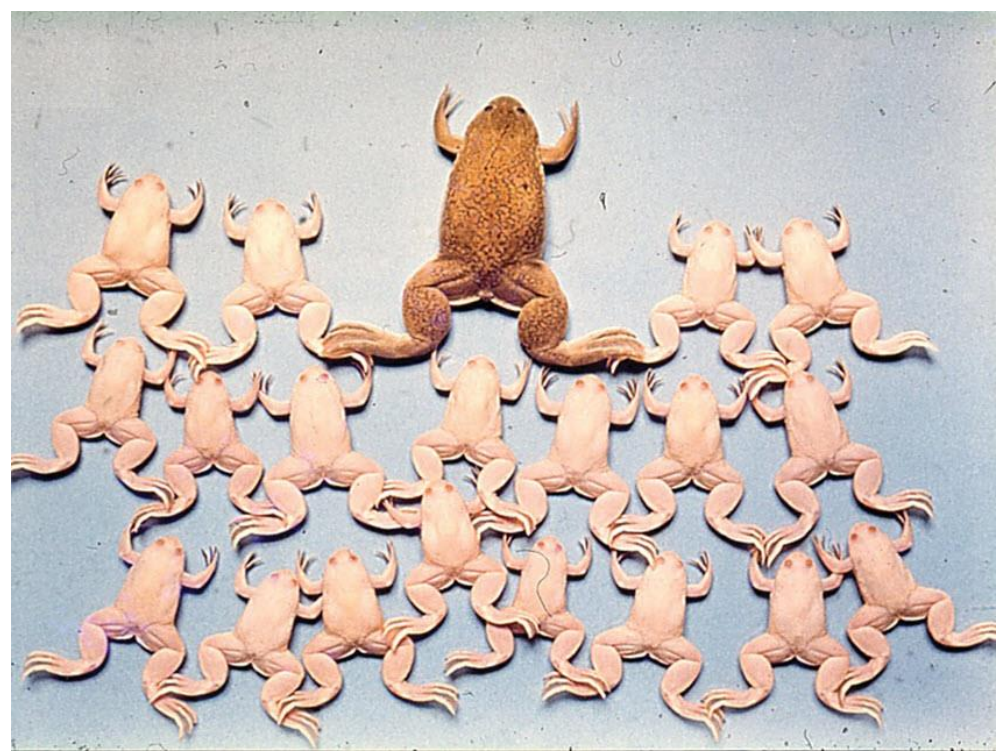

Figure 6. A Clone of Albino Male Frogs Obtained by Transplanting Nuclei from Cells of an Albino Embryo to Enucleated Eggs of the Wild-type Female.

The albino frogs are genetically identical and will accept skin grafts from each other. 
The success of these intestinal epithelium nuclear transfers differed from one experiment to another. Moreover, some females supplying recipient eggs gave significantly better development than others. Egg quality was therefore a factor. Nevertheless, these results showed that starting with nuclei from differentiated intestinal epithelium cells, with a striated border, some of the nuclear transplant embryos developed entirely normally to the feeding tadpole stage and were progressing towards metamorphosis. Furthermore, these tadpoles carried only one nucleolus per nucleus with a diploid set of chromosomes. This showed that the transplanted nucleus that gave normal development did indeed derive from an intestinal epithelium cell. Although the percentage of intestinal epithelium cell nuclear transfers that yielded entirely normal feeding tadpoles was low (1.5\%), ${ }^{6}$ many such individuals were obtained and they all carried the nuclear marker.

My supervisor and his assistant looked after my nuclear transplant tadpoles, which had by now metamorphosed into young frogs, during my absence for postdoctoral work in another field. On my return, these intestinal nuclear transplant tadpoles had become adult male and female frogs, and their fertility and ability to generate normal embryos was tested. This yielded, in 1966, our paper entitled, "Fertile' intestine nuclei". ${ }^{15}$ This therefore gave the opposite conclusion to that of the Briggs and King work with Rana pipiens. Of course, there was criticism: a graduate student, working almost alone, should not be able to repeat the results of well-established and highly respected workers Briggs and King. The use of the one-nucleolated genetic marker was crucial in persuading scientists that this Xenopus work was valid. In the course of time, it became accepted in scientific circles that cells can undergo complete differentiation, to the point of making intestinal epithelial cells of a feeding tadpole, without any loss or stable inactivation of genes needed for entirely unrelated cell lineages, and indeed for every cell type.

After these early experiments, the main conclusion was confirmed that, during the course of cell differentiation, the genome is conserved and repressed quiescent genes can be reactivated. With various colleagues, and especially R.A. Laskey, we were able to obtain normal tadpoles from adult foot web skin and from a range of adult organs such as heart, lung, etc. from cells grown out in culture from these tissues. ${ }^{16}$ Although we were able to obtain normal sexually mature male and female adult animals from the intestinal epithelium cells of a feeding tadpole and we were able to obtain feeding tadpoles from the nuclei of adult cells, we never obtained a sexually mature adult animal starting from the nucleus of another adult cell. We think that the intensely rapid cell division and DNA replication enforced on an amphibian transplanted nucleus by an activated egg has a high probability of introducing replication defects, as is seen in Rana pipiens, ${ }^{17}$ thereby greatly reducing the chance of obtaining entirely normal development from the nucleus of an adult cell.

\section{EPIGENETIC MEMORY}

In addition to the rapid DNA replication and cell division enforced on a transplanted somatic nucleus, there are other ways in which we may account for the progressively decreasing success rate of nuclear transfers from differentiating and differentiated cells. One of these is that there may be a memory of a pattern of gene expression characteristic of the differentiated state. One obvious possibility is that there could be a resistance to the reactivation of those genes which are needed for early development but which have become quiescent or repressed during cell differentiation. This possibility is discussed below under the heading of "Resistance."

Another interesting possibility is that there could be a memory of an active gene state. For example, those genes that are strongly expressed in specialized cells might fail to be switched off after nuclear transfer and might then interfere with new directions of lineage selection by nuclear transplant embryos. Methods that were not available when amphibian nuclear transfers were first carried out have now made it possible to test this idea. Nuclei were transplanted from muscle or other lineagespecific progenitor cells to make nuclear transplant embryos. Although many of the resulting nuclear transplant embryos developed abnormally, it was possible to collect enough material from partially cleaved embryos to carry out gene-specific transcript assays. The surprising result was obtained that a considerable memory of an active gene state persisted in these nuclear transplant embryos through many cell cycles of inactive transcription characteristic of early amphibian embryos. We found that the neurectoderm and endoderm lineages of nuclear transplant embryos derived from muscle progenitor nuclei often continued to express muscle genes to an excessive extent. ${ }^{18}$ The memory was imperfect, in that about half of the nuclear 


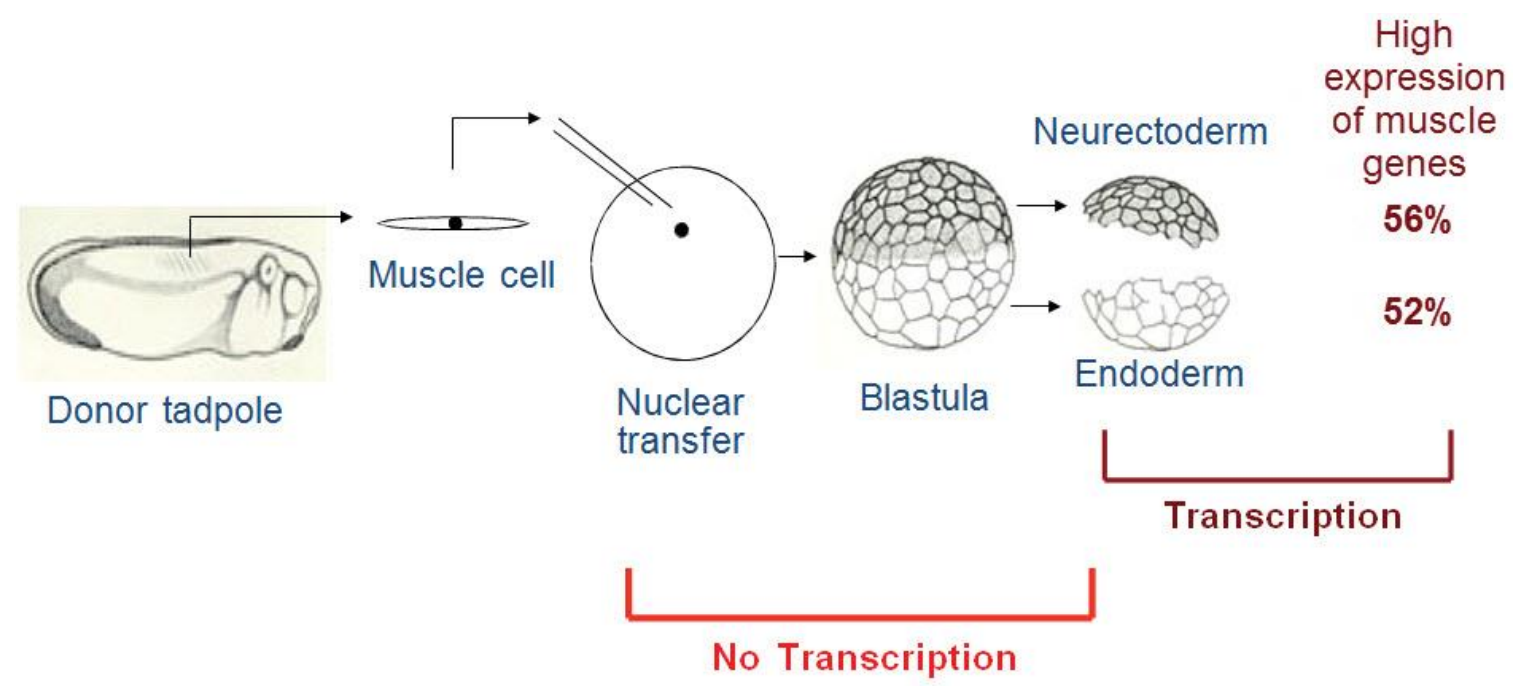

Figure 7. Epigenetic Memory in Nuclear Transplant Embryos.

Nuclear transplant embryos derived from muscle nuclei were grown to the blastula stage, and then depleted of the mesoderm region (muscle lineage). The remaining regions (neurectoderm for nerve/skin cells and endoderm for intestine lineages) express the muscle gene marker MyoD to an excessive extent in about half of all such embryos. ${ }^{20}$

transplant embryos from muscle progenitor cells showed an excessive, sometimes very large, overexpression of muscle genes in inappropriate tissues whereas the other half did not (Figure 7). Genes characteristically expressed in a certain lineage became repressed for the early cleavage divisions of a nuclear transplant embryo but then became reexpressed throughout the embryo after the stage of transcriptional activation at the late blastula stage. This result was also found in other, non-muscle lineages..$^{18}$ It was also found that this "memory" of an active gene state was associated with histone H3.3, an abundant protein in eggs and early embryos. The explanation offered for this phenomenon was that the very high level of histone normally present in oocytes and eggs ${ }^{20}$ enhances transcription of any gene that is in an active state at the time of nuclear transplantation. ${ }^{19}$ Histone H3.3 is known to be associated with active transcription. Memory of an active gene state was subsequently described in induced pluripotent stem cell (iPS) experiments. ${ }^{21}$ The observation that about $50 \%$ of nuclear transplant embryos show this memory, which is not seen in the other 50\%, exemplifies the concept (see later) that there is a conflict between components of an egg that are designed to restore gene expression to that characteristic of an egg and embryo and the resistance of the nucleus of determined or specialized cells to resist any change, thereby stabilizing the pathway of differentiation on which an embryonic cell has set out.

\section{NUCLEAR TRANSFER IN MAMMALS}

For these early results in Xenopus to be reproduced in mammals took nearly 40 years of work in sheep. ${ }^{22,23}$ A very important feature of these first successful mammalian nuclear transfers in sheep was the use of unfertilized eggs, as was actually used in amphibia. Earlier work with mice used fertilized eggs. ${ }^{24}$ Although fertilized eggs can be used,25 synchronization between nucleus and egg is harder to achieve than with the use of unfertilized eggs. A very elegant and important experiment that confirmed the general principle that cell differentiation proceeds with the retention of a complete set of genes was carried out using nuclei with a rearranged genome from mature mouse B or T donor cells. ${ }^{26} \mathrm{In}$ the course of time, somatic cell nuclear transfer to eggs has been successful in the eggs of mice and other mammals. ${ }^{27}$ In each species there seem to be some technical requirements which have to be identified and overcome. In mammals, the early cell divisions after fertilization are extremely slow compared to amphibians (20 hours from fertilization to two-cell stage in the mouse). It is therefore unlikely that the chromosome damage seen in amphibian work (above) is important in mammals. Nevertheless the decreasing success rate of nuclear transplant embryo development is about the same in mice and frogs (Figure 8). There must be other reasons for this resistance to reprogramming by eggs. 


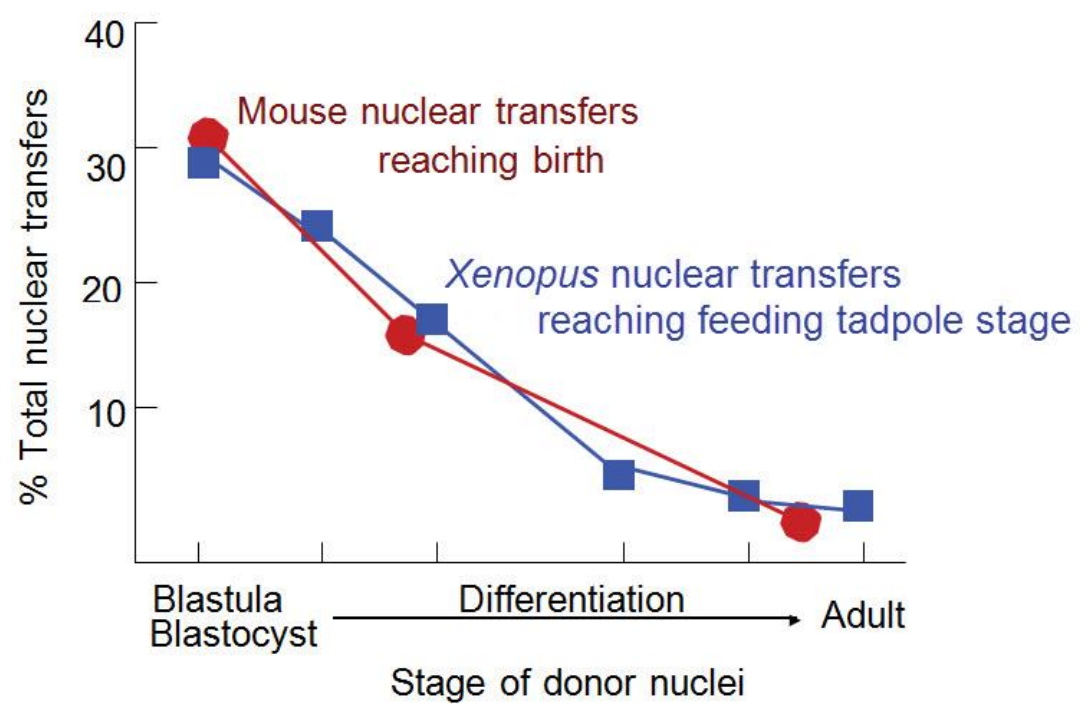

Figure 8. Survival of Nuclear Transplant Embryos in Xenopus ${ }^{6}$ and the Mouse. ${ }^{27}$

This brief history of successful somatic cell nuclear transplantation does not do justice to the many important contributions made after the early Xenopus work. For reviews of the early Xenopus work see Gurdon 1986. ${ }^{28}$ Subsequent reviews which also cover the early work have been published by McKinnell,29 DiBerardino and Hoffner,30 and by Gurdon in 2006. ${ }^{31}$

\section{MECHANISMS OF NUCLEAR REPROGRAMMING BY EGGS}

The second question raised when I was embarking on my PhD thesis on nuclear transfer in Xenopus concerned mechanisms of reprogramming. There are two parts to this question. Firstly, how does an egg reverse the differentiation state of a somatic nucleus to enable it to behave like a zygote nucleus and leading to entirely normal development? And secondly, in what way do the nuclei of somatic cells become progressively resistant to the reprogramming conditions of an egg?

To approach these questions it was clearly necessary to focus on the transcription of individual kinds of genes. At that time, in the 1960s, genes had not been cloned, and it was only possible to work with genes which were present in multiple copies per genome, such as $28 \mathrm{~S}, 18 \mathrm{~S}$, and $5 \mathrm{~S}$ ribosomal genes. Working with ribosomal genes, transfer RNA genes, and the gross class of genes whose base composition resembled the average of the genome, it was shown that transplanted somatic nuclei in blastula and gastrula stages of nuclear transplant embryos had reverted to an embryonic pattern of transcription. ${ }^{2}$ However, this did not lead to understanding the mechanism by which this rejuvenation took place. It took a few decades before single genes expressed in early Xenopus development had been cloned and the necessary probes and procedures developed by which the expression of these genes could be monitored in nuclear transplant embryos.

At this time it seemed useful to investigate the mechanisms that guide early embryo development when nuclear transplant embryos, especially from advanced donor stages, often develop very abnormally. I wondered whether the nuclear transfer techniques could be used to introduce purified macromolecules into an egg, and hence into embryonic cells. Thanks to my scientific friendship with Jean Brachet in Belgium, a major contributor to the field of developmental biology,33 I was able to acquire a small sample of purified globin mRNA from the laboratory of Dr Chantrenne. He was one of the first to purify animal mRNA. Even a few micrograms of this was more precious than gold dust, and anything that came in contact with it had to be chromic acid cleaned for fear of RNAse. A highlight of my career at this time was the discovery that purified messenger RNA could be extremely efficiently translated into protein when injected directly into an egg or embryonic cell. 34 Interestingly, this finding was completely unexpected because of the very high ribonuclease activity present in eggs. For this reason a grant application to permit such an 
experiment would not have succeeded. I was fortunate to have enough other funding to do this work without specific grant support. Amazingly it was possible to inject rabbit globin mRNA into the fertilized Xenopus egg, grow that egg to a tadpole stage, and demonstrate that tissues such as muscle were still translating high levels of globin, wholly inappropriate to that cell type, without any interference in normal development. 35 The injection of messenger RNA, and other macromolecules, into an egg has now become a very widely used procedure in developmental biology. I am still amazed at how well this works. We can now understand that the injection of an egg with a micropipette is sufficiently harmless that ribonuclease is not released from egg cytoplasm. It may be that the penetration of an egg with a micropipette is no more harmful than the penetration of an egg by sperm after fertilization. The success of the technique led to the widespread use of mRNA injection for over- and underexpression experiments in developmental biology.

A key mechanism in early development is the concentration-dependent response of cells to signaling molecules, an area known as morphogen gradient interpretation. Even two-fold differences in ligand concentration are enough to make competent embryonic cells choose which cell type lineage to follow. ${ }^{36,37}$ We now know that small quantitative deficiencies in signaling can adversely affect nuclear transplant embryo development, as shown in crossspecies nuclear transplantation. ${ }^{8}$ Another particularly interesting aspect of concentration-dependent signaling is illustrated by the community effect. 39 Resulting from single cell transplantations, the concept developed by which a group of similar cells can contribute a high enough concentration of signal molecules to exceed a threshold never produced by a single cell. This community effect seems to contribute to the normal development of multicellular tissues in development. It later turned out that the principle behind the community effect had already been proposed, as "quorum sensing," to be involved in bacteria-dependent light emission in predatory fish and in other examples. 40

To progress with the analysis of reprogramming by egg cytoplasm, an obviously desirable route would be to achieve successful reprogramming of somatic nuclei by extracts of eggs; this could lead to the identification of such components by fractionation and selective depletion. Somatic nuclei transplanted to eggs are almost immediately induced to commence DNA replication. ${ }^{41}$ Extracts of eggs are remarkably successful in inducing DNA replication in isolated nuclei,42,43 but such extracts are notoriously difficult to make in such a way that transcription proceeds meaningfully. This difficulty in making functional extracts of cells is in marked contrast to the long-lasting success of injecting messenger RNA, genes, etc. into living cells. Injecting components into eggs and early embryo cells can be regarded as "living biochemical test tubes." 44

\section{THE ANALYSIS OF NUCLEAR REPROGRAMMING BY OOCYTES}

It was evident from the earliest amphibian nuclear transfer experiments that the replication of DNA and chromosomes in somatic nuclei transplanted to eggs is very often defective. ${ }^{17}$ Once penetrated and activated by sperm or an injection pipette, amphibian eggs immediately enter a phase of some 10 or more rapid cell division cycles. It is very difficult for a somatic cell nucleus, which might normally divide once every two days, to switch immediately to a division cycle of 30 minutes. As a result, the DNA of transplanted nuclei or their daughters is often torn apart at cell division when incompletely replicated. This leads to major chromosome loss and other defects, especially when the nucleus of a slowdividing somatic cell is transplanted. It was clear, at this point, that we had to find a way of analyzing the reprogramming of somatic cell nuclei without the disadvantage and damaging effect of enforced rapid DNA replication and cell division. This led to the introduction of amphibian oocytes as somatic cell nuclear transfer recipients.

The amphibian oocyte is the growth phase of an early germ cell to a full-sized egg progenitor with lampbrush chromosomes over a period of several months. 45 These cells are in the prophase of first meiosis (Figure 9).

These full-sized egg progenitors are normally induced by hormone levels to complete first meiosis and progress to the metaphase of second meiosis, after which they can respond to fertilization. While still in my PhD graduate work, I developed the use of Xenopus oocytes to analyze the origin of the DNA replication-inducing capacity of eggs. Even sperm nuclei can be converted to lampbrush chromosomes after injection to oocytes..$^{6}$ It became clear that somatic nuclei or even pure DNA would be efficiently and correctly transcribed when injected into the germinal vesicle (=nucleus) of an oocyte. 47,48 It is important to appreciate that the germinal vesicle of 


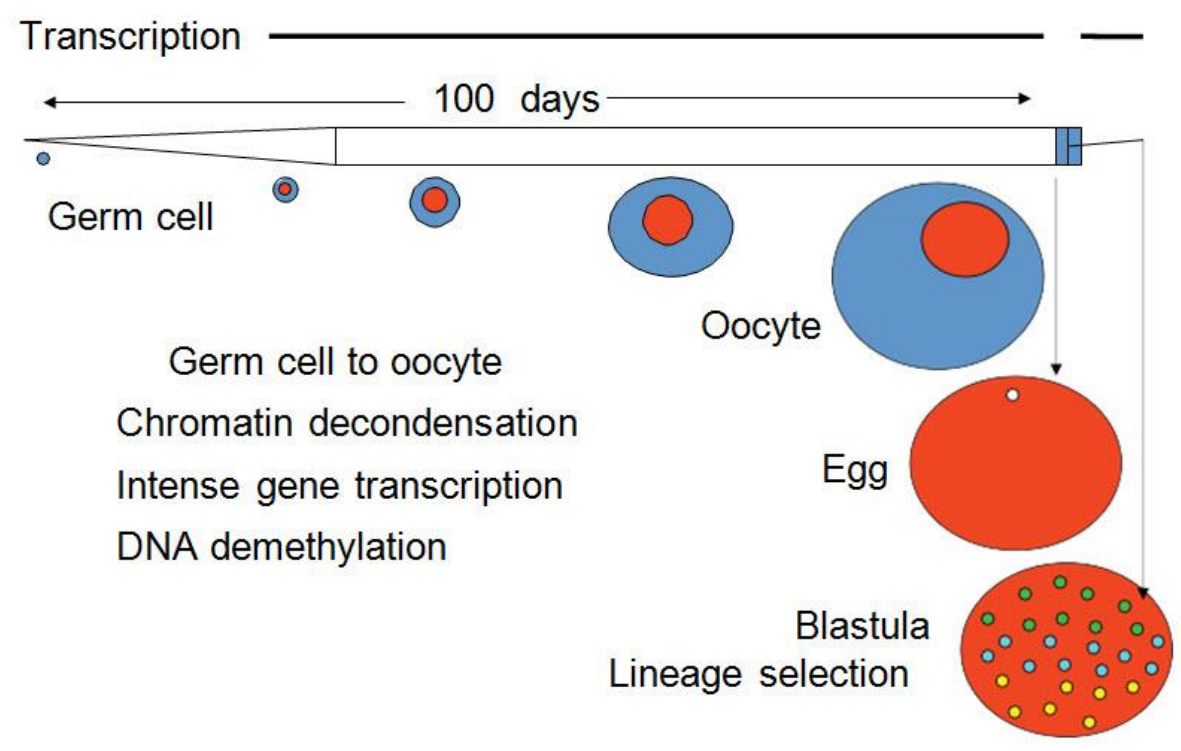

Figure 9. The Xenopus Oocyte.

The Xenopus oocyte grows in the ovary from a germ cell over many months while it is in first meiotic prophase. When fully grown it can respond to hormones, such as progesterone, to complete first meiosis and arrest in second meiotic metaphase. Once fertilized, it progresses to the blastula stage in 8 hours and somatic lineages already start to appear.

an amphibian oocyte contains an enormous reserve of developmentally essential components, which are distributed to the egg cytoplasm during completion of meiosis (Figure 10). These reserves are necessary for normal embryonic development. Fortunately for developmental biologists, these components, specified by the intensely active lampbrush chromosomes, are accumulated in the specialized germinal vesicle where they represent a high concentration of components that later enter the egg cytoplasm. Since DNA replication and cell division do not take place in these growing oocytes, the oocyte germinal vesicle provides an accessible accumulation of transcriptionally active components.

Somatic nuclei, chromatin, or DNA, of amphibian or mammalian origin, can, with practice, be injected into the invisible germinal vesicle of an

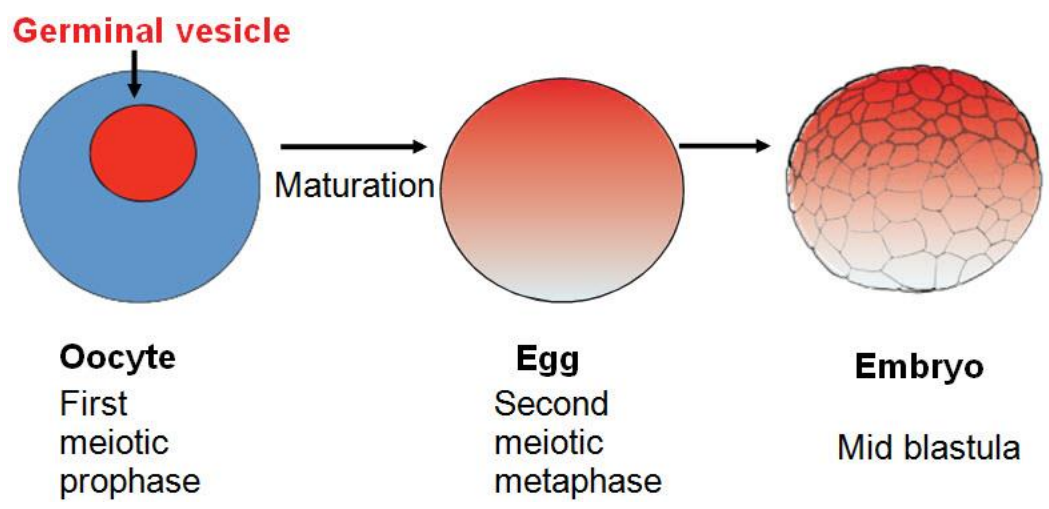

Figure 10. The Germinal Vesicle in the Xenopus Oocyte.

A Xenopus oocyte has a huge ( $420 \mu \mathrm{m}$ diameter) germinal vesicle, which includes its tetraploid chromosome set. After completion of meiosis, the germinal vesicle contents are distributed to the egg and subsequently to the embryo. 
intact oocyte. 49 Xenopus oocytes show selective transcription of somatic nuclei from unrelated species. $5^{\circ}$ Transcription of injected nuclei or genes takes place at a high rate, with as much as several hundred re-initiations of transcription on a gene per day. Two hundred to 300 somatic nuclei can be injected into one oocyte's germinal vesicle, so that one injected oocyte provides the same amount of nuclear material as 250 eggs injected with a single nucleus (Figure 11). This makes it realistic to use on oocytes those molecular techniques that normally require large amounts of material. When injecting purified DNA, this becomes chromatinized. ${ }^{1}$ Oocytes continue to transcribe injected nuclei or chromatin for several days. It is possible to isolate manually the germinal vesicle from an oocyte, containing injected somatic nuclei, and to carry out antibody binding, ferric reducing ability of plasma (FRAP) assays, etc. on individual transplanted nuclei. After injection into the germinal vesicle, somatic nuclei undergo a massive chromatin decondensation as does sperm in an egg. After transfer to oocytes, some genes are transcribed extensively and continue to accumulate large numbers of transcripts. These activated genes include some of those that are active in embryos, including the well-known pluripotency genes, such as Oct4, Sox2, Nanog, etc. These characteristics make the injected first meiotic prophase oocyte of Xenopus very suitable for analyzing both the activation of genes during reprogramming and the basis of resistance by the nuclei of differentiated somatic cells. 49

\section{TRANSCRIPTIONAL ACTIVATION}

Several necessary early steps have now been identified. The first of these is the movement of a

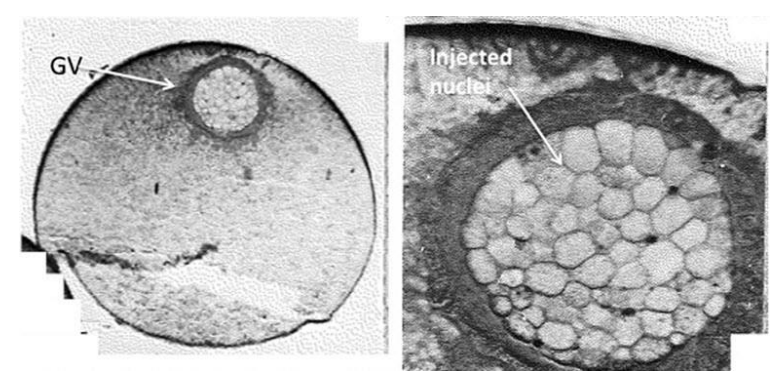

Figure 11. Multiple Somatic Nuclei can be Injected into the Germinal Vesicle of an Oocyte.

Left: Whole oocyte. Right: Germinal vesicle. special linker histone, known as B4 in amphibia or Hifoo in mammals, into transplanted nuclei. This histone protein is abundant in the germinal vesicle of amphibian oocytes, and a large amount of it is incorporated into the chromatin of injected nuclei within $2-3$ hours at $17^{\circ} \mathrm{C}$. This step is necessary for subsequent transcriptional activation, as shown by the use of antibodies and over-expressed dominant negative forms of this histone which inhibit subsequent pluripotency gene activation. ${ }^{2}$ When B4 histone invades transplanted nuclei, these nuclei lose the somatic form of linker histone. This substitution of linker histone in chromatin is likely to be an important part of the striking decondensation of chromosomes that takes place soon after nuclear injection. This early event is thought to give access of other oocyte components, including transcription factors, to injected chromatin. The B4 histone is abundant in oocytes but is not present in normal development after the blastula stage. 53 The next important events include the movement of another oocyte-specific histone, namely histone $\mathrm{H}_{3} .3$, into injected nuclei. Histone H3.3 is present in somatic cells but at a much higher concentration in oocytes and is generally associated with active transcription. We have noted above that histone $\mathrm{H} 3.3$ may be causally associated with epigenetic memory in somatic nuclei transplanted to second-metaphase eggs. If histone $\mathrm{H}_{3} .3$ has a general role of enhancing transcription, this would help to account both for epigenetic memory in nuclear transplant embryos as well as for the increasing level of transcription seen in somatic nuclei transplanted to oocytes. ${ }^{28} \mathrm{~A}$ later event is the polymerization of nuclear actin in oocytes and in nuclei transplanted to their germinal vesicles.54 This seems to enhance the level of transcription of transplanted nuclei during the first two days. This sequence of events leads to a high level of transcriptional reprogramming and takes place at a remarkably fast rate. Within two days, most of the somatic nuclei transplanted to oocytes have strongly activated transcription of the pluripotency gene Sox2; this happens at $17^{\circ} \mathrm{C}$, the metabolic equivalent of 12 hours at $37^{\circ} \mathrm{C}$.

Although the transcription of some genes, after nuclear transfer to oocytes, is enormously increased from a somatic level, up to 100 times for Sox2, the oocyte germinal vesicle does not cause a global transcriptional enhancement of all genes. The RNASeq analysis shows that most genes in a mouse somatic cell are not changed in transcription, some remaining at a high level and others remaining at a 
repressed level. A minority of genes that were active in somatic cells become repressed after transfer to oocytes, and a smaller fraction of them undergo a great enhancement of transcription. Thus the reprogramming of somatic nuclei by the oocyte germinal vesicle is highly selective (Jullien et al., unpublished). Those genes that are transcriptionally activated include ones that are strongly expressed and important in early mammalian development, including Sox2, Oct4, and Nanog. The germinal vesicle of an oocyte seems to be endowed with components that induce intense transcriptional activity, as seen in lampbrush chromosomes, for all genes that are accessible. ${ }^{9}$ However, some genes in somatic nuclei do not respond to the transcriptioninducing conditions of the egg.

\section{RESISTANCE TO REPROGRAMMING BY OOCYTES}

To me, resistance to transcriptional activation is now the most interesting aspect of nuclear reprogramming. This increasing resistance associated with development seems to reflect the remarkable stability of cell differentiation (Figure 12). Hardly ever does a cell of one specialized type switch to another cell type, or produce daughter cells that do so. Resistance to reprogramming is also evident in cell fusion experiments, 55 and even more so in iPS work..$^{6}$ The transplantation of mammalian somatic nuclei containing a repressed $\mathrm{X}$ chromosome has identified one kind of molecule responsible. Mouse embryo fibroblasts containing an inactive $\mathrm{X}$ chromosome are highly resistant to the transcription of these genes after nuclear transfer to oocytes. However, the nuclei of mouse embryo blastodisc cells that also contain an inactive $\mathrm{X}$ chromosome are strongly reactivated transcriptionally by oocytes. This difference between blastodisc and adult nuclei has turned out to be attributable to the chromosomal component macroH2A whose removal or inactivation in adult mouse embryonic fibroblast (MEF) nuclei results in transcription of pluripotency genes. ${ }^{7}$ At present, we envisage the female mammalian $\mathrm{X}$ inactivation process as a set of steps that progressively stabilize the inactive state. Thus, as development and cell differentiation proceed, successive levels of inactivation, involving histone modifications such as $\mathrm{H}_{3} \mathrm{~K} 27 \mathrm{Me} 2 / 3$ and macroH2A absorption into chromatin, and finally methylation of DNA, cause a gene to become stably repressed and highly resistant to reprogramming..$^{10}$

To analyze other ways in which genes become resistant to reprogramming, two experimental routes are likely to prove useful. One is progressively to remove components of isolated nuclei and then test their transcription in injected oocytes until resistance is lost (Halley-Stott, unpublished). This procedure is proving successful in depleting nuclei of all RNA including non-coding RNA. Increasing concentrations of $\mathrm{NaCl}$ with Triton can progressively deplete isolated nuclei of chromosomal proteins. If resistance can be restored by adding back defined fractions of released proteins, this could lead to the identification of those chromosomal proteins that confer resistance on individual genes. Another potentially valuable experimental approach is to
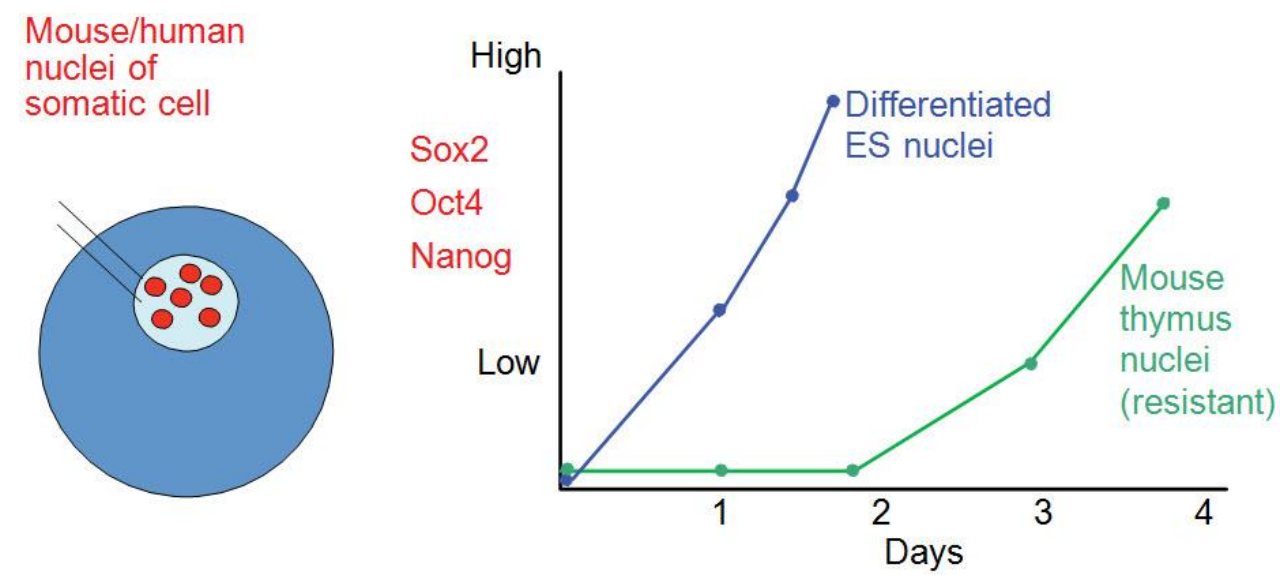

Figure 12. Somatic Nuclei Injected into the Germinal Vesicle of an Oocyte Transcribe Genes that are Quiescent in the Donor Cells but Are Rapidly Transcriptionally Activated.

The most specialized donor nuclei (mouse thymus) showed temporal resistance to transcriptional activation. 
over-express, by mRNA injection to oocytes, those enzymes that add or remove modifications to histones. It should then be possible to relate a particular histone or other chromosomal modification to the resistance of a gene to reprogramming by oocytes. By these methods, there is a prospect of understanding, in reasonable detail, the mechanisms of nuclear reprogramming and resistance in nuclei transplanted to amphibian oocytes.

\section{OVERVIEW AND PROSPECTS}

The process of nuclear reprogramming by eggs and oocytes can be seen as a conflict between the cytoplasm of an egg whose components are designed to promote rapid DNA replication and then transcription, and the components of differentiated cell nuclei whose function is to maintain a stable state. The cytoplasm of an egg is specially designed to activate the highly condensed and specialized nucleus of sperm, with $100 \%$ efficiency. Not surprisingly, the same components are effective at activating the nucleus of a somatic cell. The difference is that a somatic cell nucleus has become, during the process of cell differentiation, highly resistant to activation by egg cytoplasm in a way that is different from sperm nuclei. These nuclei of differentiated cells are provided with molecules that stabilize their differentiated state and resist reversal or rejuvenation. If differentiated cell nuclei could be too easily switched to an embryonic state, this could permit the reversal of differentiation and lead to cancer and other defects.

The experimental work described here has centered on the use of amphibian eggs and oocytes because of the abundance of material and ready availability offered by them, an advantage that was very clear to developmental biologists in the 1950 . The general principles that have emerged from work on amphibia seem also to apply to mammals and other vertebrate species. A full understanding of nuclear reprogramming by amphibian eggs and oocytes may well facilitate nuclear reprogramming in mammals including humans, and hence contribute to the eventual therapeutic application of cell replacement.

\section{REFERENCES}

1. Rauber A. Personaltheil und Germinaltheil des Individuum. Zool Anz 1886;9:166-71.

2. Spemann H. Embryonic Development and Induction. New Haven, CT: Yale University Press; 1938.
3. Briggs R, King TJ. Transplantation of living nuclei from blastula cells into enucleated frogs' eggs. Proc Natl Acad Sci U S A 1952;38:455-63. Full Text

4. Gurdon JB. The effects of ultraviolet irradiation on uncleaved eggs of Xenopus laevis. Quart J Micr Sci 1960;101:299-312.

5. Briggs R, King TJ. Changes in the nuclei of differentiating endoderm cells as revealed by nuclear transplantation. J Morph 1957;100:269-312. Full Text

6. Gurdon JB. The developmental capacity of nuclei taken from intestinal epithelium cells of feeding tadpoles. J Embryol Exp Morphol 1962;10:622-40.

7. Gurdon JB, Hopwood N. The introduction of Xenopus laevis into developmental biology: of empire, pregnancy testing and ribosomal genes. Int $J$ Dev Biol 2000;44:43-50.

8. Jaenisch R. Nuclear cloning and direct reprogramming: the long and the short path to Stockholm. Cell Stem Cell 2012;11:1-4. Full Text

9. Jullien J, Halley-Stott RP, Miyamoto K, Pasque V, Gurdon JB. Mechanisms of nuclear reprogramming by eggs and oocytes: a deterministic process? Nat Rev Mol Cell Biol 2011;12:453-9. Full Text

10. Pasque V, Jullien J, Miyamoto K, Halley-Stott RP, Gurdon JB. Epigenetic factors influencing resistance to nuclear reprogramming. Trends Genet 2011;27: 516-25. Full Text

11. Elsdale TR, Gurdon JB, Fischberg M. A description of the technique for nuclear transplantation in Xenopus laevis. J Embryol Exp Morphol 1960;8:437-44.

12. Brown DD, Gurdon JB. Absence of ribosomal-RNA synthesis in the anucleolate mutant of Xenopus laevis. Proc Natl Acad Sci U S A 1964;51:139-46. Full Text

13. Gurdon JB. Factors responsible for the abnormal development of embryos obtained by nuclear transplantation in Xenopus laevis. J Embryol Exp Morphol 1960;8:327-40.

14. Chan AP, Gurdon JB. Nuclear transplantation from stably transfected cultured cells of Xenopus. Int J Dev Biol 1996;40:441-51.

15. Gurdon JB, Uehlinger V. 'Fertile' intestine nuclei. Nature 1966;210:1240-1. Full Text

16. Laskey RA, Gurdon JB. Genetic content of adult somatic cells tested by nuclear transplantation from cultured cells. Nature 1970;228:1332-4. Full Text

17. Di Berardino MA, King TJ. Development and cellular differentiation of neural nuclear transplants of known karyotype. Dev Biol 1967;15:102-28. Full Text

18. Ng RK, Gurdon JB. Epigenetic memory of active gene transcription is inherited through somatic cell nucle- 
ar transfer. Proc Natl Acad Sci U S A 2005;102:195762. Full Text

19. Ng RK, Gurdon JB. Epigenetic memory of an active gene state depends on histone $\mathrm{H}_{3} .3$ incorporation into chromatin in the absence of transcription. Nat Cell Biol 2008;10:102-9. Full Text

20. Cho H, Wolffe AP. Xenopus laevis B4, an introncontaining oocyte-specific linker histone-encoding gene. Gene 1994;143:233-8. Full Text

21. Polo JM, Liu S, Figueroa ME, et al. Cell-type of origin influences the molecular and functional properties of mouse induced pluripotent stem cells. Nat Biotechnol 2010;28:848-55. Full Text

22. Campbell KH, McWhir J, Ritchie WA, Wilmut I. Sheep cloned by nuclear transfer from a cultured cell line. Nature 1996;380:64-6. Full Text

23. Wilmut I, Schnieke AE, McWhir J, Kind AJ, Campbell KHS. Viable offspring derived from fetal and adult mammalian cells. Nature 1997;385:810-13. Full Text

24. McGrath J, Solter D. Inability of mouse blastomere nuclei transferred to enucleated zygotes to support development in vitro. Science 1984;226:1317-19. Full Text

25. Egli D, Rosains J, Birkhoff G, Eggan K. Developmental reprogramming after chromosome transfer into mitotic mouse zygotes. Nature 2007;447:67985. Full Text

26. Hochedlinger K, Jaenisch R. Monoclonal mice generated by nuclear transfer from mature $\mathrm{B}$ and $\mathrm{T}$ donor cells. Nature 2002;415:1035-8. Full Text

27. Wakayama T, Perry AC, Zuccotti M, Johnson KR, Yamagimachi R. Full-term development of mice from enucleated oocytes injected with cumulus cell nuclei. Nature 1998;394:369-74. Full Text

28. Gurdon JB. Nuclear transplantation in eggs and oocytes. J Cell Sci Suppl 1986;4:287-318. Full Text

29. McKinnell RG. Cloning: Nuclear Transplantation in Amphibia. Minneapolis, USA: University of Minnesota Press; 1978.

30. DiBerardino MA, Hoffner NJ. Gene reactivation in erythrocytes: nuclear transplantation in oocytes and eggs of Rana. Science 1983;219:862-4. Full Text

31. Gurdon JB. From nuclear transfer to nuclear reprogramming: the reversal of cell differentiation. Ann Rev Cell Dev Biol 2006;22:1-22. Full Text

32. Woodland HR, Gurdon JB. RNA synthesis in an amphibian nuclear-transplant hybrid. Dev Biol 1969;20:89-104. Full Text

33. Brachet J. Biochemical Cytology. New York: Academic Press; 1957:516.
34. Gurdon JB, Lane CD, Woodland HR, Marbaix G. The use of frog eggs and oocytes for the study of messenger RNA and its translation in living cells. Nature 1971;233:177-82. Full Text

35. Woodland HR, Gurdon JB, Lingrel JB. The translation of mammalian globin mRNA injected into fertilized eggs of Xenopus laevis. II. The distribution of globin synthesis in different tissues. Dev Biol 1974;39:134-40. Full Text

36. Green JB, Smith JC. Graded changes in dose of Xenopus activin A homologue elicit stepwise transactions in embryonic cell fate. Nature 1990;374:391-4. Full Text

37. Dyson S, Gurdon JB. The interpretation of position in a morphogen gradient as revealed by occupancy of activin receptors. Cell 1998;93:557-68. Full Text

38. Narbonne P, Simpson DE, Gurdon JB. Deficient induction response in a Xenopus nucleocytoplasmic hybrid. PLoS Biol 2011;9:e1001197. Full Text

39. Gurdon JB. A community effect in animal development. Nature 1988;336:772-4. Full Text

40. Lamb RF. Amino acid sensing mechanisms: an Achilles heel in cancer? FEBS J 2012;279:2624-31. Full Text

41. Graham CF, Arms K, Gurdon JB. The induction of DNA synthesis by frog egg cytoplasm. Dev Biol 1966;14:349-81. Full Text

42. Laskey RA, Fairman MP, Blow JJ. S phase of the cell cycle. Science 1989;246:609-14. Full Text

43. Mechali M. Eukaryotic DNA replication origins: many choices for appropriate answers. Nat Rev Mol Cell Biol 2010;11:728-38. Full Text

44. Gurdon JB. Molecular biology in a living cell. Nature 1974;248:772-6. Full Text

45. Callan HG. The Croonian Lecture, 1981. Lampbrush chromosomes. Proc R Soc Lond B Biol Sci 1982;214: 417-48. Full Text

46. Gall JG, Murphy C. Assembly of lampbrush chromosomes from sperm chromatin. Mol Biol Cell 1998;9: 733-47. Full Text

47. Mertz JE, Gurdon JB. Purified DNAs are transcribed after microinjection into Xenopus oocytes. Proc Natl Acad Sci U S A 1977;74:1502-6. Full Text

48. Brown DD, Gurdon JB. High fidelity transcription of $5 \mathrm{~S}$ DNA injected into Xenopus oocytes. Proc Natl Acad Sci U S A 1977;74:2064-8. Full Text

49. Halley-Stott RP, Pasque V, Astrand C, et al. Mammalian nuclear transplantation to germinal vesicle stage Xenopus oocytes-a method for quantitative transcriptional reprogramming. Methods 2010;51:56-65. Full Text 
50. De Robertis EM, Gurdon JB. Gene activation in somatic nuclei after injection into amphibian oocytes. Proc Natl Acad Sci U S A 1977;74:2470-4. Full Text

51. Wyllie AH, Gurdon JB, Price J. Nuclear localization of an oocyte component required for the stability of injected DNA. Nature 1977;268:150-2. Full Text

52. Jullien J, Astrand C, Halley-Stott RP, Garrett N, Gurdon JB. Characterization of somatic cell nuclear reprogramming by oocytes in which a linker histone is required for pluripotency gene reactivation. Proc Natl Acad Sci U S A 2010;107:5483-8. Full Text

53. Smith RC, Dworkin-Rastl E, Dworkin MB. Expression of a histone H1-like protein is restricted to early Xenopus development. Genes Dev 1988;2:1284-95. Full Text
54. Miyamoto K, Pasque V, Jullien J, Gurdon JB. Nuclear actin polymerization is required for transcriptional reprogramming of Oct4 by oocytes. Genes Dev 2011;25:946-58. Full Text

55. Blau HM, Chiu CP, Webster C. Cytoplasmic activation of human nuclear genes in stable heterokaryons. Cell 1983;32:1171-80. Full Text

56. Yamanaka S. Induced pluripotent stem cells: past, present, and future. Cell Stem Cell 2012;10:676-84. Full Text

57. Pasque V, Gillich A, Garrett N, Gurdon JB. Histone variant macroH2A confers resistance to nuclear reprogramming. EMBO J 2011;30:2373-87. Full Text 